\section{Sewing needle migrating from esophagus into prevertebral space: A challenging case}

\author{
Nilam Uttam Sathe, Sheetal Shelke, \\ Ratna Priya, Kamini Chavan \\ Department of Ear, Nose, Throat and \\ Head-Neck Surgery, Seth G. S. Medical \\ College and KEM Hospital, Mumbai, \\ India
}

\begin{abstract}
Oesophageal foreign body presents as a medical emergency and requires immediate evaluation and treatment. We are reporting a rare case of sewing needle in esophagus migrating into the prevertebral space at thoracic inlet level. A 13-year-old mentally retarded female child was brought in emergency at midnight with complaint of accidental ingestion of sewing needle with the thread. Patient was posted for rigid esophagoscopy under general anaesthesia, no needle could be visualised and only thread of the sewing needle was removed. So patient was taken up for neck exploration along with gastroenterologists. Further careful dissection confirmed the needle in the pre vertebral space, which was removed successfully with artery forceps. Patient was given IV antibiotics for 10 days. Patient had an uneventful recovery and was discharged after 10 days. Pointed metallic slender foreign bodies can perforate and migrate very fast in the neck or chest and can lead to morbidity and mortality. Multidisciplinary approach offers a great advantage in surgical planning and proper patient management.
\end{abstract}

\section{Introduction}

Oesophageal foreign body presents as a medical emergency and requires immediate evaluation and treatment. The increased incidence is usually seen in children due to their natural inquisitiveness for the surroundings as well as increase in hand to mouth activity. In adults, the involuntary ingestion of foreign bodies usually occurs as a result of certain predisposing factors, such as dentures, decreased sensitivity of the oropharyngeal mucosa, alcoholism, neurological and psychiatric disorders. ${ }^{1,2}$ Also associated esophageal pathologies such as strictures, diverticula, malignancy, and achalasia may further facilitate esophageal foreign body impaction.

We are reporting a rare case of sewing needle in esophagus migrating into the prevertebral space at thoracic inlet level.

\section{Case Report}

A 13-year-old mentally retarded female child was brought in emergency to the department of ENT, Seth G. S. Medical College and KEM Hospital at midnight with complaint of accidental ingestion of sewing needle with the thread. The mother had informed that she was seewing the clothes and had to attend the phone call on her mobile phone, the child was sitting on her lap. After that the needle and thread was missing and the thread was seen hanging out through the child mouth. She tried to pull it out but was unsuccessful in removing the needle and thread as it was stuck up inside. The child came with hanging thread out of her mouth, drooling of saliva, painful dysphagia. However there was no associated chest pain, dyspnea or hemoptysis. Patient was afebrile and hemodynamically stable. General examination revealed thread of sewing needle coming from oral cavity. There was no sign of subcutaneous emphysema in neck. Chest X-ray confirmed the presence of radio-opaque foreign body in the esophagus (Figure 1).

Patient was posted for rigid esophagoscopy under general anaesthesia. On esophagoscopy, no needle could be visualised and only thread of the sewing needle was removed. So patient was taken up for neck exploration along with gastroenterologists. On table repeat chest and abdominal X-ray revealed the oblique lie of the foreign body and possibility of being present in the retropharyngeal or pre vertebral space. Neck exploration was performed using right lateral cervical incision. The sternocleidomastoid and carotid sheath was retracted laterally and esophagus was retracted medially. Esophageal wall was palpated and did not reveal any foreign body. Further careful dissection confirmed the needle in the pre vertebral space (Figure 2) which was removed successfully with artery forceps (Figure 3). Nasogastric tube was placed under esophagoscopic guidance for 10 days. Post op chest X-ray was normal. Patient was given IV antibiotics for 10 days and oral feeds were started after 10 days. Patient had an uneventful recovery and was discharged after 10 days.

\section{Discussion}

Foreign bodies of the upper aerodigestive tract are one of the most common emergencies in everyday ENT practice.
Correspondence: Nilam Uttam Sathe, Department of Ear, Nose, Throat and HeadNeck Surgery, Seth G. S. Medical College and KEM Hospital, Patidar Complex, B/304, Kannamwar Nagar No. 2, Vikhroli-East, Mumbai 400083 Maharashtra, India.

Tel.: +91.98209298.

E-mail: drneelam_s@yahoo.co.in

Key words: Migrating esophageal sewing needle; Prevertebral space.

Contributions: the authors contributed equally.

Conflict of interest: the authors declare no potential conflict of interest.

Funding: none.

Ethical standard: ethical approval and informed consent were not required according to Danish regulations. The study was approved by the Danish Data Protection Agency (No. 2014-41-3568).

Received for publication: 30 January 2017. Revision received: 5 November 2017.

Accepted for publication:8 November 2017

This work is licensed under a Creative Commons Attribution NonCommercial 4.0 License (CC BY-NC 4.0).

(C) Copyright N.U. Sathe et al., 2018

Licensee PAGEPress, Italy

Surgical Techniques Development 2018; 8:7073 doi:10.4081/std.2018.7073

Commonly found objects in adults include fish bones, chicken bone, dentures, coins, and needles. ${ }^{3}$ These foreign bodies can be impacted in the tonsils, valeculla, pyriform sinus and the cervical esophagus and thus can easily be removed by esophagoscopy.

The symptoms are mostly sudden onset and patients report immediately for medical help. Radio opaque foreign bodies are easily visualised on antero-posterior and lateral neck X-rays but they may not be very helpful in locating the exact site in case migration occurs. Foreign body migration can be diagnosed on the basis of suggestive history, a positive finding on lateral neck radiography, and a negative finding on rigid oesophagoscopy. ${ }^{4}$ Frequent complications of foreign-body migration include retropharyngeal abscess, perforation of the esophagus, perforation of the aorta, and migration through the common carotid artery., ${ }^{4,5}$ In such cases, most authors suggest exploration of neck and immediate foreign body removal. ${ }^{4-6}$ Computed tomography scan can be of great help in diagnosing the exact location of foreign body and plan the 


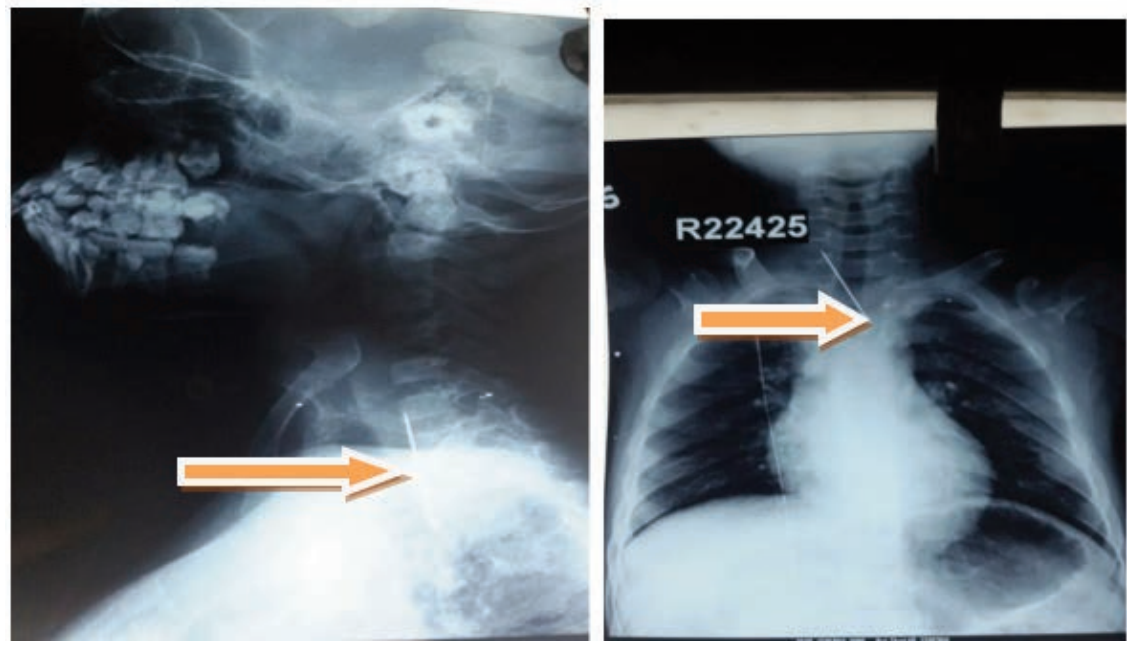

Figure 1. AP and lateral view of $\mathrm{X}$-ray neck showing needle in prevertebral space.

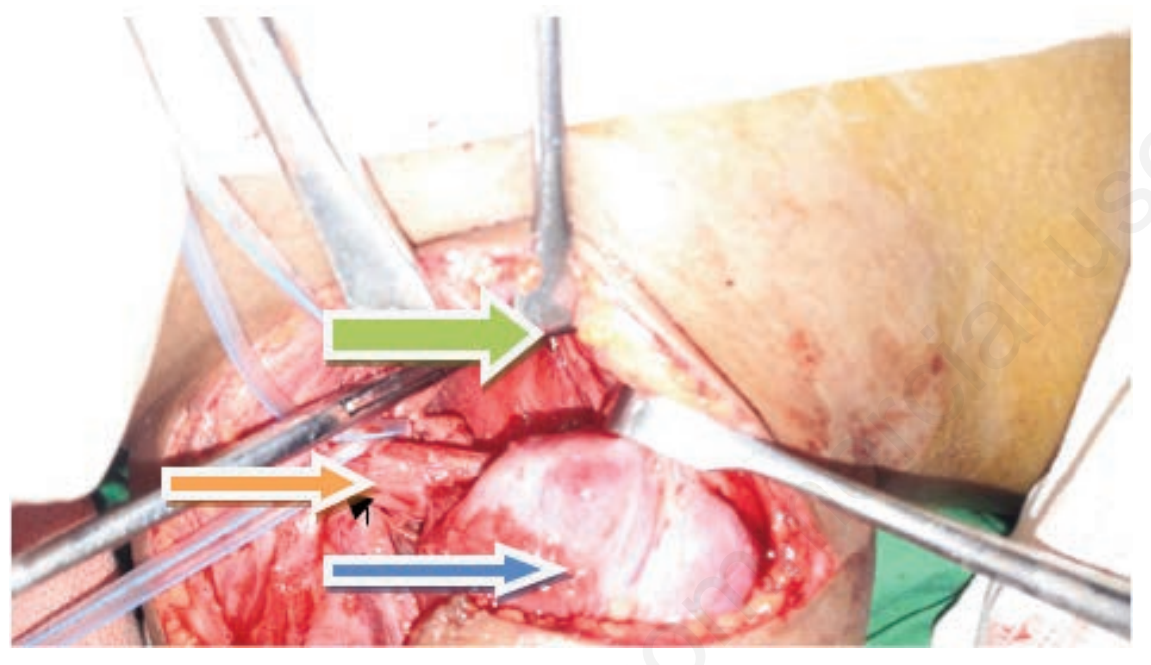

Figure 2. Intraoperative picture showing tip of needle (freen arrow) in prevertebral area at thoracic inlet area (orange arrow: esophagus; blue arrow: thyroid gland).

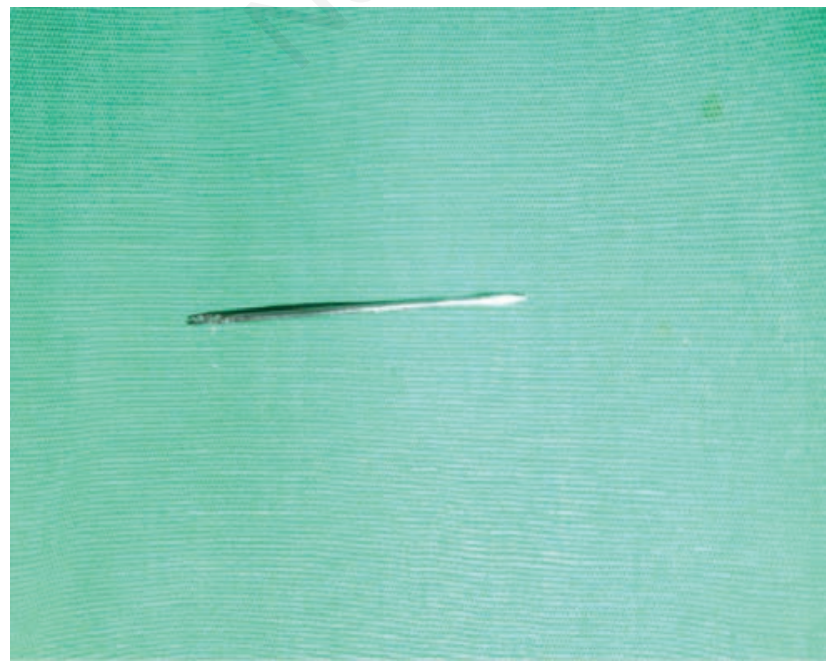

Figure 3. Metallic needle after surgical exploration. surgery.

Penetration of esophageal wall and migration of foreign bodies is rarely encountered. Possible reasons could be: strong esophageal peristaltic movements against the foreign body, neck movement and careless manipulation of the foreign body while trying to remove it may increase the risk of perforation. The incidence is around $1 \%$ and $4 \%{ }^{7}$ The foreign body can even migrate through the esophageal wall and may become impacted in the soft tissues of the neck in some cases. ${ }^{8-10}$ Migrating foreign bodies can either remain silent or may lead to life threatening complications such as deep neck abscess, mediastinitis or vascular complications (penetration of the carotid artery, jugular vein or their branches). ${ }^{11}$

In our case, since the foreign body couldn't be seen on esophagoscopy, the possibility of migration was kept in mind. We sought the help of gastrosurgeons in case the foreign body was present in the wall; esophagotomy was also kept as an option. Neck exploration was done by both the ENT and gatsrosurgeons. Meticulous dissection and by careful palpation of the surrounding neck structures, the needle was located in the pre vertebral space.

\section{Conclusions}

The diagnosis of a migrating foreign body requires a high index of suspicion and early intervention is necessary so as to avoid complications. Pointed metallic slender foreign bodies can perforate and migrate very fast in the neck or chest and can lead to morbidity and mortality. A thorough esophagoscopy and careful and systematic approach during neck exploration is must. Multidisciplinary approach offers a great advantage in surgical planning and proper patient management.

\section{References}

1. Adhikari P, Shreshtha BL, Baskota DK, Sinha BK. Accidental foreign body ingestion: Analysis of 163 cases. Int Arch Otorhinolaryngol 2007;11:26770.

2. Hazra TK, Ghosh AK, Roy P, et al. An impacted meat bone in the larynx with an unusual presentation. Indian $\mathrm{J}$ Otolaryngol Head Neck Surg 2005;57:145-6.

3. Chee LW, Sethi DS. Diagnostic and therapeutic approach to migrating foreign bodies. Ann Otol Rhinol Laryngol 1999;108:177-80. 
4. Tatheer Z, Mubasher I, Moghira I, et al. Migrating foreign body in the thyroid gland, an unusual case. J Ayub Med Coll Abbottabad 2006;18:65-6.

5. Osinubi OA, Osiname AI, Pal A, et al. Foreign body in throat migrating through the common carotid artery. Laryngol Otol 1996;110:793-5.

6. Costa HD, Bailey F, McGavigan B, et al. Perforation of the oesophagus and aorta after eating fish: an unusual cause of chest pain. Emerg Med J 2003;20:385-6.

7. Scher RL, Tegtmeyer CJ, Mc Lean WC. Vascular injury following foreign body perforation of the esophagus: review of the literature and report of a case. Ann Otol Rhinol Laryngol 1990;99:698-702.

8. Sreetharan SS, Prepageran N, Satwant $\mathrm{S}$. Unusual migratory foreign body in the neck. Singapore Med J 2004;45:487.
9. Jemerin EF, Amoff JS. Foreign body in thyroid following perforation of oesophagus. Surgery 1949;25:52-9.

10. Muhanna AA, Abu Chra KA, Dasti H, et al. Thyroid lobectomy for removal of a fish bone. J Laryngol Otol 1990;104:511-2.

11. Remsen K, Lawson W, Biller HF, Som ML. Unusual presentations of penetrating foreign bodies of upper GIT. Ann Otol Rhinol Laryngol 1983;105:32-44. 